\title{
Methodology for the Regional Landfill Site Selection
}

\author{
Boško Josimović and Igor Marić
}

Additional information is available at the end of the chapter

http://dx.doi.org/10.5772/45926

\section{Introduction}

One of the most important causes of environmental pollution is certainly an inadequate waste management. The three factors that have primarily influenced this problem area are: ever increasing amount of municipal solid waste (which causes increasingly pronounced space occupation), increasing amount and types of hazardous waste, as well as lack of awareness on the importance of acting promptly in this field. Particular problems in waste management occur in developing countries, where the awareness of the importance of environmental protection has not yet achieved a satisfactory level and where, out of economic or political reasons, professional guidelines associated with waste management are not observed. Problems emerge either due to a lack of legislation, or obsolete legislation, lack of trained personnel, inadequate waste management infrastructure, financial constraints in the establishment of a modern waste management system, population lacking the awareness about solid waste management, impossibility of selecting appropriate space for landfill development, lack of standards, etc.

Great problems in waste management in Serbia are caused by increasing amount of waste, lack of sanitary landfills built under international standards (which is inefficient and ecologically acceptable), as well as by the fact that the principle of hierarchy in waste management is not observed at all. Problems emerging in the field of environmental pollution and the manner of responding to pollution through the planning documentation, only increase the importance of this problem area.

Waste management is a complex process which implies a control of the entire waste management system (from waste generation, through collection and transportation of waste, to waste treatment and disposal), along with the support of legislation and appropriate institutional organization. The accent in the present paper is placed on spatial 
planning as an inevitable instrument for strategic waste management. The paper also points out the importance of spatial aspect in the waste management planning process.

\section{Disposal of solid waste}

The final functional element in the waste management system is waste disposal. Waste disposal is a final fate of all types of waste, either municipal solid waste, collected and transported directly to landfills, or industrial waste or other materials from waste treatment facilities which are of no use-value any longer [1].

Landfill forms the basis of every waste management plan, because there will always be waste to be disposed of.

Sanitary landfills are sites selected for waste disposal, such as natural or artificial (excavated) depressions, engineered facilities, where the waste is, through appropriate technological processes, compacted as densely as practicable to minimize its volume and covered with a layer of soil or some other material in a systematic and sanitary manner. Before proceeding with such work, a terrain to be used must be selected, surveyed and prepared [2].

Sanitary landfills are necessary in any combination, even for some other form of solid waste treatment, because there will always be waste to be disposed of. Uncontrolled dumps must be closed along with necessary sanitation. This requires knowledge of a series of notions, processes and activities which should enable proper landfill planning, design, construction, exploitation and funding, as well as control of landfill environmental impacts [3].

\section{Spatial aspect of waste management}

Considering that waste management system is realized in space, it is quite clear that characteristics of space greatly determine the choice of an adequate management system, i.e. its spatial organization. This primarily refers to the selection of sites having physical elements of the system, such as, primarily, sanitary landfills, transfer stations, recycling centers, etc. In this context, physical-geographical and anthropogenetic characteristics of space are of great importance. Relative to these characteristics, conceptual solutions to the waste management system are defined, and landfill site selection process is carried out for elements of the waste management system.

\subsection{Requirements for the regional landfill site selection}

In the waste disposal process, a controlled disposal procedure is unavoidable, either for the disposal of genuine waste or materials that remain after the treatment process, or, as necessary, if the main process cannot be carried out in certain period because of interruption, defect, overhaul, or out of other reasons. Sanitary landfills are necessary in any chosen waste management option, because there will always be waste to be disposed of on landfills. In this sense, locating potential landfill sites, as the most commonly used process 
through which a huge amount of collected waste is treated, should be given great attention in the waste management process, i.e. in spatial planning process. This is a very delicate and very important process from the viewpoint of the protection of key environmental factors (land, water and air), landscape values, as well as the protection of population health [4]. Out of this reason, it is also necessary to dedicate great attention to the investigation of a character, as well as potential and real landfill impact on the environment. This enables the elaboration and implementation of measures to eliminate or minimize negative effects.

Sanitary landfill planning and construction is only a part of a complex solid waste management process which encompasses the treatment of waste from its generation, through minimization of its amount, selection, recycling, collection, transport and disposal, to landfill recultivation and bringing of land to new use. However, although sanitary landfills are only a part of a wider waste management process, this activity is characterized by a very complex and long-term process which must take into account natural and anthropogenetic characteristics of space.

Sanitary landfill is available land for solid waste disposal at which engineering methods of waste disposal are used in a manner in which threats to the environment are minimized. The landfill site selection and technology of devices and equipment for sanitary waste treatment and disposal should be in the function of the protection and rational use of space.

Sanitary landfill development implies activities in several phases where certain sequence must be obeyed. The process is usually carried out in four phases:

- landfill site selection (site investigation process),

- identification of a landfill site (through the planning documentation) and elaboration of conditions for bringing it to the intended use,

- elaboration of construction (technical) documentation,

- landfill construction.

\subsubsection{Preconditions for sanitary landfill construction}

It is necessary to consider the following requirements and requirements for sanitary landfill construction:

- Spatial and urban planning requirements

- Spatial and regional requirements

- Landfill site selection

- $\quad$ Required land area

- Transportation distances

- Local site conditions

- Topography

- Climate conditions

- Hydrogeological conditions

- Geological conditions 
- Geo-mechanical conditions

- Environmental protection

Landfill site selection.- In planning, landfill site selection occupies extremely important place. In the widest sense, the natural, social, political, economic and technical factors have an important role in landfill site selection, thus it follows that the selection is to be made by a multidisciplinary team of experts. Given that landfill construction is considered as a noneconomic activity, a special task is to select landfill site from the aspect of the use of buildable land and its price, as well as other natural or urban values which have an important role in relation to rationality and planned landfill remediation or its rehabilitation, i.e. reconstruction [5]. From technical and technological aspects, for the planning, design, construction and exploitation needs, it is necessary that on each landfill site the following is ensured:

- Complete sanitary security for people living in the surrounding residential areas, as well as personnel working at landfills

- Protection of land, air, ground and surface water from pollution

- Rational use of land, as well as save land (increased levels of waste compaction using special machines, as well as a deposition height)

- Maximum number of machines and equipment for all types of works

\subsection{Implementation of GIS tools in waste management}

Information system is an arranged set of information on things and facts in surroundings, with the aim to get acquainted with a system. Right decision making in planning and space organization depends to a great extent on knowledge, i.e. the quality and importance of information available to decision makers.

The GIS is a powerful set of computer tools for collecting, storing, searching as necessary, transformation and display of real-world data for various purposes [6].

As one of the most complex information systems that cover all spatial problems, the GIS has many advantages out of which the most significant are:

- It covers all elements of geo-space and ecological elements

- It includes natural and social elements of space

The use of GIS is appropriate for:

- $\quad$ Spatial planning

- Mapping for various purposes

- Traffic planning

- Waste management planning

- Natural resource inventory and management

- Computer mapping of population and entering of census data

- Creating hazard maps and programs of procedures in such cases, etc. 
Essentially, GIS contains data on:

- Air

- Earth's surface

- Water areas

- Lithosphere

- Soil

- Biocenosis

- Anthropogenetic spatial elements, etc.

The GIS, as already mentioned, consists of spatial data and descriptive data.

Spatial data refer to locations, i.e. spatial relationships between phenomena and objects. They are obtained based on literature, maps, aerial photos taken from aircrafts, etc., and they are useful only if they can be converted into maps.

Descriptive data are linked to localities, polygon line or body and are the system accompanying content.

The GIS key features are:

- Possibility of spatial search of phenomena

- Possibility of overlapping contents and combining individual contents into a new quality

- Logical operations with spatial and descriptive data

Geographic information systems are most frequently compatible with most of related systems (geodetic, agricultural, geologic, mining, water resources management, forestry, urban planning systems, etc.), but also with census databases, statistical information systems, technological databases, databases associated with health, education, science, etc. Using GIS mapped data, we carry out precisely what an information system should enable: solve a problem, make queries, reach answers, or examine possible solutions. Here, data are manipulated digitally, and not manually, because we manipulate the data on events and activities using digital cartographic objects. In other words, the points, lines and areas in this cartographic database are used for data management.

Therefore, the GIS is a general tool for problem solving. It is created for making a certain project. A successful GIS is built, not bought, and indented for analysts to draw out relevant data for forecasting and planning, as well as various pieces of information associated with a specific space, as well as the problem area which is a subject of analysis.

The role of GIS tools in waste management planning is dominant in landfill site selection process. In addition, GIS tools are also used for distribution and identification of locations for other elements of waste management system such as transfer station network, waste selection and processing centers, for defining transportation corridors, etc.

The method of multicriteria analyses and evaluation is used for identifying locations of elements of a waste management system in the GIS. This approach is inevitable in locating 
complex objects, such as, for example, regional municipal solid waste landfills. Its complexity is reflected both in the size and function of objects, as well as in relation to various possible spatial impacts, also in negative context.

The use of GIS in defining strategies, analyses and visualization of solutions and alternatives helps us consider and clearly represent various scenarios, as well as select the most suitable solutions through a prism of different relevant criteria (spatial, ecological, hydro-geological criteria, etc.) [7].

Therefore, in using the GIS in the selection of the most suitable landfill sites, two things of key importance are [8].:

1. Analysis of space, i.e. all of its physical-geographical and anthropogenetic characteristics. It is necessary to comprehensively consider the space on which the problem is to be solved or which can be useful for problem solving. In this process, because of social sensitivity associated with this issue, it is necessary to be impartial in considering a possible landfill site. This can only be achieved if the entire space is considered to the same level of detail and in the same manner;

2. Visualization of space and its characteristics and impacts. This is necessary so that all participants in the project could have equal chance to perceive and understand the subject problem area. This enables active participation in searching for solutions to an acceptable compromise [9]. All participants must consider the space, as well as its advantages and disadvantages for landfill site selection. This is precisely one of the most important advantages of using GIS tools in landfill site selection, as well as of choosing other elements of a waste management system.

Defining landfill site selection criteria is the main step in landfill site selection process. In the first phase, based on exclusiveness, the sites which do not satisfy these criteria are eliminated. Positive areas within which it is possible to search for the most suitable solutions are the result of this process. This phase represents an activity of microzoning. Using GIS tools, through overlapping cartographic presentations of a certain space carried out based on exclusion criteria, it is rather simple to eliminate unsuitable landfill sites.

After eliminating the unsuitable landfill sites, the attention is dedicated to the nomination of landfill sites within the remaining "conditionally suitable" zones. In this process, local governments and professional institutions can and must be of great importance, but soil investigations and collecting relevant data on physical-geographical and anthropogenetic characteristic of space are indeed of utmost importance.

Through nominating potential landfill sites, preconditions for the selection of the most suitable landfill site are created, which is followed by multicriteria analysis and evaluation of candidate sites. Site selection criteria are entered into tables and weighted for each candidate site based on the entered value scale. In this way, the evaluation process using GIS tools is carried out in an efficient manner and in a short period of time.

The role of GIS tools in the landfill site selection process is in that it enables faster singling out and clearer presentation of suitable and unsuitable sites based on previously given criteria. 
In this context, it is evident that selection criteria and value scale for evaluation of candidate landfill sites are of key importance in this process, while GIS tools represent a powerful means which to a great extent facilitate and speed up the process. This refers not only to the landfill site selection process, but also to defining the spatial organization of the entire waste management system, as well as defining the transfer station network.

\subsection{Landfill site selection criteria}

\subsubsection{Landfill site selection criteria}

The most important step in this process is to define landfill site selection criteria.

There are two groups of criteria. The first group includes the so-called exclusion criteria that are used in the first phase of the landfill site selection process. Exclusion criteria are defined relative to the specific situation and they represent restriction criteria.

Some of exclusion criteria can be classified into a group of the following indicators:

- Distance from natural elements of space (watercourses, water sources, protected natural resources, etc.)

- Distance from anthropogenetic elements of space (infrastructure facilities, settlements, protected cultural structures, etc.)

- Terrain morphology

- Hydrological and geological characteristics of space

- Degradation of space

- Recommendations of local authorities in a form of intermunicipal corporation agreements, etc.

According to exclusion criteria, areas which should not be further analyzed are discarded, i.e. areas that will be analyzed and evaluated in consecutive phases singled out. In the elimination phase, a single-criterion method is mainly used.

After that, in cooperation with local institutions and experts, certain number of sites are nominated for which a multicriteria evaluation is carried out. In this context, criteria based on which each candidate site will be evaluated in the same way are defined. This is a second group of criteria.

Site evaluation criteria are mainly classified into several basic groups. Commonly, there are three basic groups of criteria whose definition varies from author to author:

- Ecological or environmental criteria,

- Socio-economic or social or spatial criteria,

- Technical and operational criteria (which usually also involve certain economic, spatial and ecological criteria).

Any variation of groups of basic indicators is possible. Regardless of the formulation of basic groups of criteria, they include approximately either the same or almost the same number of indicators and criteria that are analyzed and compared in the process of selection of the most suitable site for a landfill. 
Number of landfill site selection criteria ranges from 20 to over 40 . They are classified (or not classified) into groups of criteria to which they belong, which are also similar, but can be differently formulated.

A particularly sensitive and important step in landfill site selection that follows the choice of relevant criteria is to define value scales based on which each individual criteria is evaluated (valued, ranked). Each criteria is assigned its corresponding weight (value) which is determined based on expert's evaluation and evaluation of participants in the process of sanitary landfill site selection. Here, quantitative evaluation is commonly used (e.g. scores from 1 to 10 , or from 1 to 5).

Qualitative/expert assessment can also be used, where criteria can be assessed as suitable, conditionally suitable or unsuitable. Qualitative assessment is today increasingly less used, because the use of new technologies enable more accurate and more sophisticated assessment under the principle of quantitative assessment. In this case, accurate and objective data are obtained that can be compared and used for making right decisions.

When a potential site is assessed according to all given criteria, it is possible to carry out the following two steps:

1. Adding up all obtained scores

2. Multiplying the obtained scores by importance values (weights).

The first step in evaluating candidate sites is the simplest one and will low requirements. The best score is obtained through adding up all obtained scores for each criterion. Evaluation of candidate site in this case does not have different scenarios that can be of great help to decision makers.

The second step is more complex as different scenarios can be used. For example, if criteria for locating candidate landfill site are classified into several basic groups, then the number of scenarios to be considered is consistent with the number of criteria groups. Criteria from one group are favored in the first scenario, the most important criteria in the second scenario are those from the second group, and so on. The final option is a situation when groups of criteria are multiplied by the same importance value, without favoring any of criteria group. By presenting the scenarios in synthesis Table, it is easy to identify which candidate sites are the most suitable in which scenarios. The PROMETHEE method [10] is an example of this approach.

The basic advantage of this procedure is in that decision makers have a clear idea of which is candidate site is the most suitable if criteria from a certain group of criteria (ecological or economic or spatial, etc.) are assessed as the most worthwhile criteria, and if basic criteria groups are dealt with equally. This greatly facilitates decision making. Regardless of which of the many methods for evaluation of potential landfill sites are used, the question of objectivity of the procedure arises taking into account that the selection of evaluation elements (criteria, weights), but also the very decision-making process, is a matter of objectivity of experts and decision makers. This can be considered 
as a common disadvantage of all methods for potential landfill site selection. Therefore, the subjectivity in this process must be minimized to the utmost limit, while objectivity must be maximized.

\section{Case study: Regional landfill site selection in the Kolubara region in Serbia}

\subsection{Analysis of the present state in the Kolubara region}

We have chosen the area of the Kolubara Region comprising 11 municipalities with 382,000 inhabitant as an example of theoretical knowledge presented in the first part of the present paper.

The Study on the Selection of Micro-location for the Regional Landfill with Recycling Centre and Regional Center for Municipal Solid Waste Management, Regional Plan for Solid Waste Management, as well as Strategic Environmental Assessment (SEA) for the same Plan have been elaborated for the Kolubara Region.

Municipal waste from the territory of 11 municipalities in the Region is disposed of to 10 unarranged sanitary city landfills and a certain number of illegal dumps. All existing landfills should be closed or remediated and recultivated in the shortest possible time. It is recommended to prolong the life-time of the existing landfills through the mentioned remediation projects. Recognizing the need for the final, contemporary waste disposal and management, 11 municipalities of the Region have united together in forming the regions for the development of a waste management. The initiatives that have been launched in this context have resulted in the elaboration of the "Study on the Selection of Micro-Location for the Regional Municipal Waste Landfill with Recycling Center for the Kolubara Region", based on which the location for regional landfill has been selected.

\subsection{Locating the regional landfill site for Kolubara Region}

The sanitary landfill construction implies carrying out activities in several phases, whereby it is necessary to observe a specific sequence. The process is mainly carried out in four phases as follows:

1. Identifying (selecting) the location

2. Determining the location (through the planning and design documentation) and creating conditions for bringing land to intended use

3. Elaborating the construction documents (technical documentation)

4. Landfill construction

The most sensitive and the most important step in making a concept of regional municipal solid waste management is a regional landfill site selection. Relative to the selected regional landfill site, other elements of a waste management system are also located and their spatial distribution carried out. 
Once the selection of the most suitable landfill site is made, it is necessary to incorporate it in the planning solutions in order to create conditions for the elaboration of technical documentation, as well as for landfill construction.

\subsection{Regional landfill site selection criteria}

The elaboration of the Study on Landfill Site Selection represents the first step in making a concept of municipal solid waste management in the Kolubara Region.

The first step in landfill site selection is to define exclusion criteria.

Taking into account current legislation, Intermunicipal Agreement on Joint Waste Management, basic exclusion criteria used in practice, available data on the space, as well as relevant characteristics of a specific space, the following exclusion criteria have been defined, see [6]:

- $\quad$ Seismic activity over 9 MCS

- Distance of less than 500 meters from watercourses

- Distance of less than 500 meters, or $1.5 \mathrm{~km}$ from settlements, if not sheltered

- Distances of less than 500 meters from water supply sources

- Collision with the existing planning documents

- Distance of less than 500 meters from roads of the first category if the site is not sheltered

- Terrains with an inclination of over $30 \%$

- Terrains of more than 300 meters above sea level

- Alluvial plains and karst terrains

Their corresponding areas have been identified using the GIS tools. Through overlapping the corresponding areas, the following is obtained:

1. Potentially suitable areas for landfill

2. Unsuitable areas within which it is not possible to locate the landfill.

Once the potentially suitable areas within which its is possible to search for the regional landfill site are singled out, the regional plans for waste management for the Kolubara District and Belgrade administrative area have been considered in which the area of the Kolubara lignite basin has been determined for a macro-location for the regional municipal waste landfill.

Besides, in the Intermunicipal Agreement on the Joint Waste Management it has been agreed that the landfill site will be located in the territory of the $\mathrm{Ub}$ municipality since $\mathrm{Ub}$ has agreed to accept the waste generated in the newly formed region for municipal solid waste management in its territory.

The location of Carić (within the territory of the Valjevo municipality) has been also considered taking into account that this location has been previously analyzed several times and assessed as a suitable site for a landfill. 
In nominating the location, the following has been taken into account:

- Preliminary analyses of the entire area and possible central position of potential sites in the region

- Data collected during field visits

- Consultations and recommendations of relevant local institution and experts

- Guidelines set by the EU and the Waste Management Strategy of the Republic of Serbia

- Data and information from the existing planning documentation.

Based on the above mentioned, the following three potential landfill site locations have been proposed (Figure 1).

1. Location KALENIĆ, in the area of open pits in the Ub territory

2. Location BOGDANOVICA, city landfill (dump) in $\mathrm{Ub}$

3. Location CARIĆ, for which certain investigations have already been carried out which have indicated certain advantages for landfilling. The location is within the territory of Valjevo municipality.

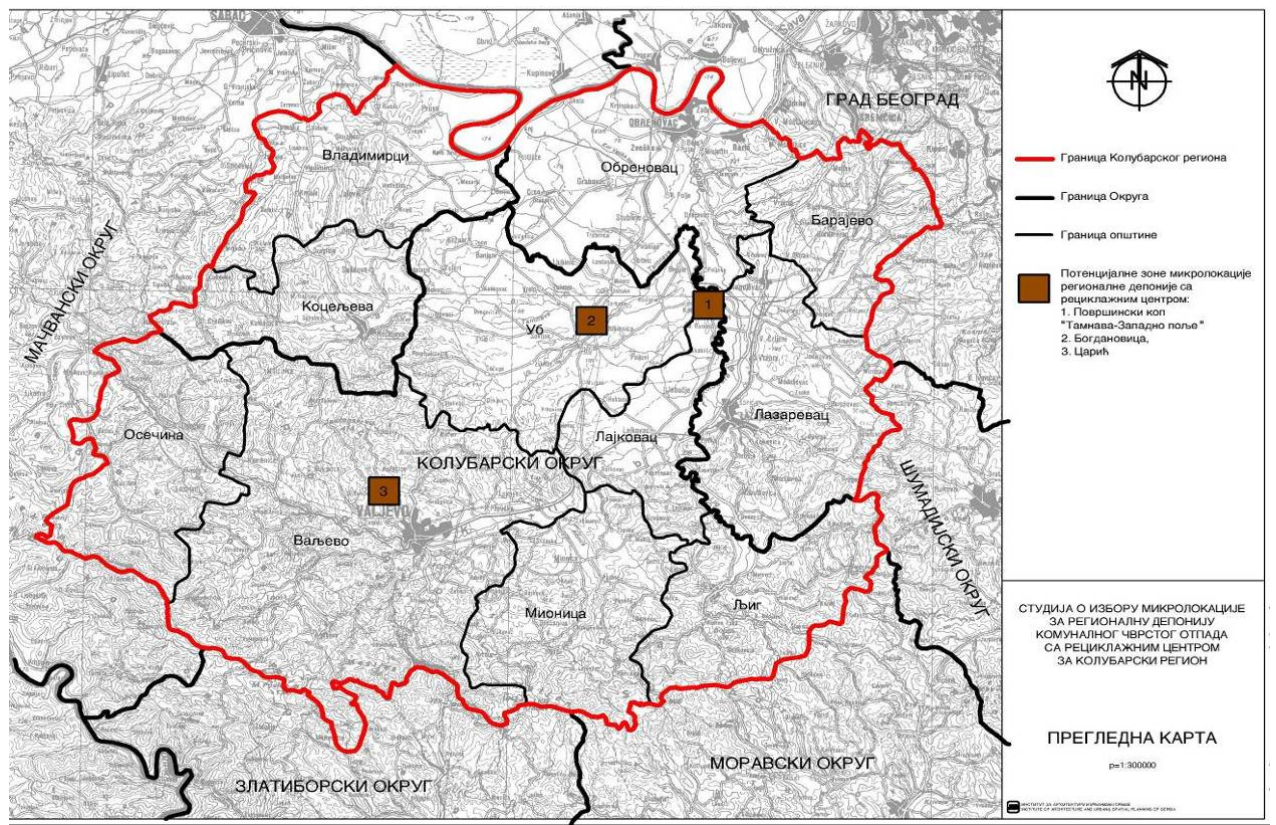

Figure 1. Position of potential landfill sites in the Kolubara Region

After the nomination of locations, the criteria for the evaluation and selection of the most suitable landfill site have been defined.

New criteria have been defined based on investigation and analysis of previous experiences of other countries and the EU guidelines, as well as on available relevant data for their evaluation. In this context, the following criteria for the selection of micro-location for 
regional landfill in the Kolubara Region for the municipal solid waste management have been defined:

\section{Hydrogeological characteristics}

a. Rock masses with fissure-cavernous porosity and a high water permeability (karstified rocks, limestones and dolostones)

b. Rocks with intergranular porosity, coarser grained rocks (coarse-grained gravel)

c. Rocks with low porosity (alluvial and glacial sediments)

d. Materials with a low water permeability, mainly impermeable complexes of $10-6 \geq k \geq$ $10-9 \mathrm{~m} / \mathrm{s}$, or with a low water impermeability, but with small layer thickness of less than $1.0 \mathrm{~m}$;

e. Water impermeable materials (clay, flysch) of $\mathrm{k} \leq 10-9 \mathrm{~m} / \mathrm{s}$, the layer thickness $\geq 1.0 \mathrm{~m}$.

\section{Ground water}

a. Aquifer is, over a brief period and at high water levels of greater frequency, above the bottom of the landfill in one part of its bottom area, while at other water levels, it is beneath the bottom; occasional flooding also occurs at the landfill site

b. Aquifer, at high water levels of small frequency, rarely rises above the landfill bottom; wetting of the landfill bottom is possible

c. Aquifer at water levels of 1 to $3 \mathrm{~m}$ is beneath the landfill bottom

d. Aquifer at high water levels $>3 \mathrm{~m}$ is beneath the landfill bottom

e. Aquifer does not exist

\section{Distance from the boundaries of zones of sanitary protection of water supply sources}

Distance from the boundary of

(a) narrower protection zone:(b) wider protection zone:

a. 0 to $0.2 \mathrm{kmbelt}$ along the protection zone contours

b. $\quad 0.2$ to $0.5 \mathrm{kmup}$ to $0.5 \mathrm{~km}$

c. $\quad 0.5$ to $1.0 \mathrm{~km} 0.5$ to $1.0 \mathrm{~km}$

d. 1.0 to $1.5 \mathrm{~km} 1$ to $2 \mathrm{~km}$

e. more than $1.5 \mathrm{~km}>2 \mathrm{~km}$

4. Geological-tectonic characteristics

a. Pronounced fault zone

b. Fault carbonate rock masses with numerous surface and underground karst shapes or flat terrain

c. Flysch sediments, shales, marlsones, sandstones, etc.

d. Glacial sediments

e. Magmatic rocks

5. Distance from the closest settlements with concentrated development or residential zones of urban settlements

a. Distance $1.5-2 \mathrm{~km}$, or $0.75-1 \mathrm{~km}$ if shelter

b. $2-3 \mathrm{~km}$, or $1-1.5 \mathrm{~km}$ with shelter 
c. up to $4 \mathrm{~km}$, or $1.5-2.0 \mathrm{~km}$ with shelter

d. up to $5 \mathrm{~km}$, or $2.0-2.5 \mathrm{~km}$ with shelter

e. more than $5 \mathrm{~km}$, or more than $2.5 \mathrm{~km}$ with shelter

6. Relief characteristics of the terrain

a. Broken relief, very uneven terrain, particularly pronounced in karst landscapes, incompact (scattered) spatial entity encompassing several valleys

b. Broken relief, uneven terrain, compact spatial entity

c. Incompact (scattered) spatial entity encompassing several valleys, naturally shaped terrain suitable for formation of valleys

d. compact waste entity, naturally shaped for locating a landfill site in a steep terrain or in natural depression

e. Mildly inclined or flat terrain, naturally shaped for locating a landfill site or possibly a landfill in excavated depressions or on earth fills

7. Available space for waste disposal and ancillary facilities

a. up to 5 yrs

b. up to $10 \mathrm{yrs}$

c. up to 15 yrs

d. up to $20 \mathrm{yrs}$

e. $20 \mathrm{yrs}$

8. Site acceptability

a. General landfill site disagreement

b. General agreement, but disagreement from local community

c. General agreement, but disagreement from certain individuals form local community

d. General agreement and somewhat moderate disagreement from local community

e. General acceptance of a landfill site

9. Engineering-geological characteristics

a. Incoherent rock masses, unstable slopes, slides and falls, active landslides

b. Complex of incoherent and semi-coherent rock masses (deluvial sediments), possible occurrence of landslides due to undercutting the foot of an existing slope

c. Semi-coherent rocks, possible occurrence of landslides due heavy falls

d. Coherent rocks, slightly stoned rock, stable slopes

e. Solid rocks, stable slopes even those of greater inclinations

10. Current land use

a. Cultivated agricultural land (ploughland, orchards), individual houses and other residential buildings within holdings, sportsgrounds, etc.

b. Quality tall forests;

c. Meadows

d. Pastures, shrub woods

e. Uncultivated land, thickets, barren land, excavations, quarries 


\section{Distance from individual water supply (wells)}

a. $\quad 100-200 \mathrm{~m}$, downstream of the landfill or approximately on landfill level

b. up to $500 \mathrm{~m}$, downstream of the landfill or on the same level as the landfill

c. 500 to $1000 \mathrm{~m}$, downstream or on the same level as the landfill

d. downstream of the landfill at the distance up to $200 \mathrm{~m}$, downstream of the landfill at the distance of $1-1.5 \mathrm{~km}$;

e. downstream of the landfill at the distance of more than $200 \mathrm{~m}$, downstream of the landfill at the distance of more than $1.5 \mathrm{~km}$.

12. Landscape characteristics

a. Highly disturbed and completely changed natural ambience during landfill exploitation and after its closure

b. Highly disturbed natural ambience during landfill exploitation, and partly after the landfill closure

c. Natural ambience disturbed during landfill exploitation, and to a less extent after its closure

d. Natural ambience slightly disturbed during landfill exploitation, and undisturbed after its closure

e. Ambience not disturbed either during landfill exploitation or after its closure.

\section{Linear distance from roads and railroads}

more important roads | other roads

without shield | with shield | without shield | with shield
a. $\quad 500 \mathrm{~m} / 300 \mathrm{~m} / 300 \mathrm{~m} / 200 \mathrm{~m}$
b. $\quad 600 \mathrm{~m} / 400 \mathrm{~m} / 400 \mathrm{~m} / 250 \mathrm{~m}$
c. $\quad 800 \mathrm{~m} / 500 \mathrm{~m} / 500 \mathrm{~m} / 300 \mathrm{~m}$
d. $1000 \mathrm{~m} / 600 \mathrm{~m} / 600 \mathrm{~m} / 400 \mathrm{~m}$
e. $>1000 \mathrm{~m} \mathrm{l}>600 \mathrm{~m} \mathrm{l}>600 \mathrm{~m} \mathrm{l}>400 \mathrm{~m}$

14. Distance to sacral structures, monuments of culture or protected natural resources

a. Distance $1.0-1.25 \mathrm{~km}$, or $0.5-0.75 \mathrm{~km}$ where there is a shield

b. $\quad 1.25-1.50 \mathrm{~km}$, or $0.75-1,0 \mathrm{~km}$ with shield;

c. $\quad 1.5-2.0 \mathrm{~km}$, or $1.0-1.25 \mathrm{~km}$ with shield;

d. $2-2.5 \mathrm{~km}$, or $1.25-1.5 \mathrm{~km}$ with shield;

e. more than $2.5 \mathrm{~km}$, or more than $1.5 \mathrm{~km}$ with shield

15. Seismic Activity
a. 9-8 MCS
b. $7 \mathrm{MCS}$
c. $6 \mathrm{MCS}$
d. $5 \mathrm{MCS}$
e. <5 MCS 
16. Existing site infrastructure

a. Absence of any infrastructure

b. Poor infrastructure

c. Only one infrastructure segment (access road, water supply line, electricity);

d. Several infrastructure segments

e. All or most of the infrastructure segments

17. Distance from surface watercourses

a. Permanent rivers or standing waters at the distance of 500 to $1000 \mathrm{~m}$, there is a risk of flooding during high waters, defense measures against high waters required

b. Small watercourses, permanent or periodic ones (brooks, torrents), there is a flood risk, it is necessary to displace or channel these waters

c. Heavy inflow of rain waters from immediate catchments, defense against these waters requires more complex facilities; there is no flooding

d. Permanent watercourses at the distance greater than $1 \mathrm{~km}$, no risk from flooding; defense standard solutions applicable

e. Great distance from watercourses, no risk from flooding, very low inflow of rain waters, simple protection against these waters possible

18. Terrain preparation

a. Very complex terrain leveling works, including intensive blasting on the greatest part of the site

b. Complex terrain leveling works, blasting required only in some parts of the landfill site

c. Terrain leveling works on the greatest part of the landfill site using machines

d. Terrain leveling on the smaller part of landfill site using machines

e. Simple terrain leveling works on the smaller part of the landfill site

19. Earth for covering the disposed waste - distance from the borrow site

a. greater than $5 \mathrm{~km}$,

b. $2-5 \mathrm{~km}$,

c. $1-2 \mathrm{~km}$,

d. up to $1 \mathrm{~km}$,

e. on site.

20. Position of the site in the Region

a. Completely dislocated relative to the central position in the Region; at the edge of the Region

b. Within the radius of $20 \mathrm{~km}$ relative to the central point in the Region,

c. Within the radius of $10 \mathrm{~km}$ relative to the central point in the Region,

d. Centrally positioned relative to the Region,

e. Within the radius of $10 \mathrm{~km}$ relative to the central point in the Region, but closer to the municipalities with the largest amounts of municipal solid waste.

21. Ownership of land

a. $100 \%$ of land under private ownership, greater number of smaller plots

b. $100 \%$ of land under private ownership, greater plots 
c. About $75 \%$ of land under private ownership, about $25 \%$ of land under state ownership

d. About $50 \%$ of land under private ownership and about the same amount of land under private ownership

e. $100 \%$ of land under state ownership

22. Precipitations

a. $1500 \mathrm{~mm}$

b. 1000 to $1500 \mathrm{~mm}$

c. 600 to $1000 \mathrm{~mm}$

d. 300 to $600 \mathrm{~mm}$

e. $<300 \mathrm{~mm}$

\section{Air temperature}

a. $<6^{\circ} \mathrm{C}$

b. $6-9^{\circ} \mathrm{C}$

c. $9-12^{\circ} \mathrm{C}$

d. $2-15^{\circ} \mathrm{C}$

e. $>15^{\circ} \mathrm{C}$

24. Air flow

a. Very frequent high intensity winds, with prevailing wind direction towards settlements and other localities where people stay and work

b. Less frequent lower intensity winds with prevailing wind direction towards relevant facilities

c. Prevailing winds of changeable direction towards relevant facilities

d. Dominant winds blowing in the opposite direction, from settlements and other places where people stay and work, as well as low intensity winds blowing in direction towards the settlements

e. Most of the winds blowing in opposite direction, from settlements and other places where people stay and work

25. Distance to individual houses outside settlements
a. $<250 \mathrm{~m}$
b. $\quad 500 \mathrm{~m}$
c. $\quad 1000 \mathrm{~m}$
d. $1500 \mathrm{~m}$
e. $500 \mathrm{~m}$

26. Site shelterness

a. Visible from all distances and all angles

b. Locality sheltered to a smaller extent

c. Locality sheltered to a greater extent

d. The glimpse of the locality can be caught in the great distance

e. Not at all visible, except when you come in the locality itself 


\section{Access road - reconstruction, or construction of a new road}

New roadRoad reconstruction
a. $>1000 \mathrm{~m},>1500 \mathrm{~m}$
b. $500-1000 \mathrm{~m} 800-1500 \mathrm{~m}$
c. $200-500 \mathrm{~m} 300-800 \mathrm{~m}$
d. $<200 \mathrm{~m}<300 \mathrm{~m}$
e. There is an access road of satisfactory characteristics

28. Providing electricity supply via the distribution network at the distance of:
a. $>2 \mathrm{~km}$
b. $1-2 \mathrm{~km}$
c. $\quad 0.5-1 \mathrm{~km}$
d. $300-500 \mathrm{~m}$
e. $<300 \mathrm{~m}$

\section{Water supply in the locality}

a. From the public water supply system via connection longer than $4 \mathrm{~km}$, or from a local water supply via a connection longer than $3 \mathrm{~km}$

b. From the public water supply system via connection 2 to $4 \mathrm{~km}$ long, or from a local water supply via a connection up to $3 \mathrm{~km}$ long

c. From the public water supply system via connection from 1 to $2 \mathrm{~km}$ long, or from a local water supply via connection up to $1 \mathrm{~km}$ long

d. From the public water supply system via connection from 0.5 to $1 \mathrm{~km} \mathrm{long}$, or from a local water supply via connection up to $500 \mathrm{~m}$ long

e. From the public water supply system via connection up to $500 \mathrm{~m}$ long

30. Distance to agricultural land
a. $<100 \mathrm{~m}$
b. $\quad 100-300 \mathrm{~m}$
c. $300-500 \mathrm{~m}$
d. $500-1000 \mathrm{~m}$
e. $>1000 \mathrm{~m}$

31. Distance from the main transmission line, gas pipeline, crude oil pipeline, drinking water pipeline
a. up to $100 \mathrm{~m}$
b. $\quad 100-200 \mathrm{~m}$
c. $200-300 \mathrm{~m}$
d. $300-500 \mathrm{~m}$
e. $500 \mathrm{~m}$

32. Possibility of construction in phases and extension

a. No possibility of construction in phases or of extension

b. Limited possibility of construction in phases, but not of extension

c. Possibility of construction in phases, but not ofextension 
d. Possibility of construction in phases and of limited extension

e. Possibility of construction in phases and of unlimited extension

Criteria are presented under the principle of exclusion criteria. More precisely, no detailed guidelines for evaluation have been given for criteria save for exclusion criteria which define requirements which a potential site MUST meet in locating the municipal solid waste landfill site.

\subsection{Implementation of multicriteria evaluation method in landfill site selection}

Potential micro-location for regional landfill in the Kolubara Region has been determined through multicriteria analysis and evaluation. Chosen criteria have been evaluated by assigning scores from 1 to 5 for each candidate site.

At the same time, depending on their importance in evaluating the locality quality, criteria have been classified into 3 pondering categories (PC). Each weight category has its specific value - weight, which is multiplied by the score of corresponding criteria. In this way, a final score is obtained for each criterion. Values by pondering categories are:

- $\quad \mathrm{PC} 1=1$

- $\quad \mathrm{PC} 2=1.5$

- $\quad \mathrm{PC} 3=3$

The relation between pondering categories (PC) is: $\mathrm{K}_{\mathrm{i}+1}=\mathrm{K}_{\mathrm{i}} / 1.5$

\begin{tabular}{|c|c|c|}
\hline PC 3 & PC 2 & PC 1 \\
\hline \multicolumn{3}{|c|}{ Landfill site selection criteria } \\
\hline $1-8$ & $9-20$ & $21-32$ \\
\hline
\end{tabular}

Table 1. Grouping the criteria by pondering categories (PC)

Table 2 indicates that after assigning a score to each criterion, the Kalenić location has been singled out as the most suitable one. The other two locations (Bogdanovica and Carić) have been assigned much poorer scores compared to the Kalenić location. However, in cases when the difference in ranks between candidate locations is extremely small at the end of evaluation process, it is difficult to make a final decision on which site is the most suitable. In this case, it necessary to carry out an additional evaluation which implies the evaluation of candidate sites by different scenarios. The chosen site selection criteria are then grouped into basic groups, while in the "additional" valuation process, the criteria from one of the basic groups are favored in each scenario, see [6].

There are so many scenarios as groups, plus one for the scenario according to which each basic criteria group is evaluated equally (for the last scenario, the data taken from basic evaluation or criteria are multiplied by weight value). In this way, decision makers are given opportunity to choose the option based on their policy, and thus select the most suitable site.

In regional landfill site selection for Kolubara Region, no "additional" evaluation has been required due to evident advantages of location Kalenić. 


\begin{tabular}{|c|c|c|c|c|}
\hline Criteria & PC & Kalenić & Bogdanovica & Carić \\
\hline 1. Hydrogeological characteristics & PC 3 & 12 & 9 & 9 \\
\hline 2. Groundwater & PC 3 & 15 & 6 & 12 \\
\hline $\begin{array}{l}\text { 3. Distance from the boundaries of zones of sanitary } \\
\text { protection of } \\
\text { water supply sources }\end{array}$ & PC 3 & 12 & 15 & 15 \\
\hline 4. Geological-tectonic characteristics & PC 3 & 12 & 9 & 9 \\
\hline $\begin{array}{l}\text { 5. Distance from the nearest settlements with concentrated } \\
\text { development or residential zones of urban settlements }\end{array}$ & PC 3 & 12 & 3 & 12 \\
\hline 6. Relief characteristics of the terrain & PC 3 & 15 & 15 & 12 \\
\hline 7. Available space for waste disposal and ancillary facilities & PC 3 & 15 & 3 & 6 \\
\hline 8. Site acceptability & PC 3 & 15 & 6 & 6 \\
\hline 9. Engineering-geological characteristics & PC 2 & 3 & 3 & 3 \\
\hline 10. Current land use & PC 2 & 7.5 & 7.5 & 1.5 \\
\hline 11. Distance from individual water supply (wells) & PC 2 & 7.5 & 7.5 & 7.5 \\
\hline 12. Landscape characteristics & PC 2 & 7.5 & 4.5 & 1.5 \\
\hline 13. Linear distance from roads and railroads & PC 2 & 7.5 & 1.5 & 7.5 \\
\hline $\begin{array}{l}\text { 14. Distance to sacral structures, monuments of culture or } \\
\text { protected natural resources }\end{array}$ & PC 2 & 7.5 & 7.5 & 7.5 \\
\hline 15. Seismic Activity MCS & PC 2 & 3 & 3 & 3 \\
\hline 16. Existing site infrastructure & PC 2 & 7.5 & 3 & 1.5 \\
\hline 17. Distance from surface watercourses & PC 2 & 6 & 1.5 & 7.5 \\
\hline 18. Terrain preparation & PC 2 & 4.5 & 4.5 & 4.5 \\
\hline $\begin{array}{l}\text { 19. Earth for covering the disposed waste - } \\
\text { distance from the borrow site }\end{array}$ & PC 2 & 7.5 & 3 & 1.5 \\
\hline 20. Position of location in the Region & PC 2 & 7.5 & 6 & 3 \\
\hline 21. Ownership of land & PC 1 & 5 & 4 & 1 \\
\hline 22. Precipitation & PC 1 & 3 & 3 & 3 \\
\hline 23. Air temperature & PC 1 & 2 & 2 & 2 \\
\hline 24. Air flow & PC 1 & 4 & 4 & 3 \\
\hline 25. Distance to individual houses outside the settlement & PC 1 & 3 & 2 & 1 \\
\hline 26. Location shelterness & PC 1 & 5 & 3 & 4 \\
\hline 27. Access road - reconstruction or construction of new road & PC 1 & 3 & 3 & 1 \\
\hline $\begin{array}{l}\text { 28. Providing electricity supply via the distribution } \\
\text { network at the distance of }\end{array}$ & PC 1 & 3 & 3 & 2 \\
\hline 29. Water supply in the locality & PC 1 & 4 & 3 & 1 \\
\hline 30. Distance to agricultural land & PC 1 & 5 & 4 & 1 \\
\hline $\begin{array}{l}\text { 31. Distance from main transmission line, gas pipeline, crude } \\
\text { oil pipeline, drinking water pipeline }\end{array}$ & PC 1 & 5 & 2 & 5 \\
\hline 32. Possibility of construction in phases and extension & PC 1 & 5 & 3 & 2 \\
\hline \multicolumn{2}{|l|}{\begin{tabular}{|c|} 
Total sum of criteria scores \\
\end{tabular}} & 231.5 & 154.5 & 154 \\
\hline
\end{tabular}

Table 2. Evaluation of potential site by chosen criteria, see [2].

Had the final results of evaluation for all candidate locations been equal, the "additional" evaluation process would have been carried out in a manner as described in the text that follows. Namely, chosen criteria for additional evaluation would be classified into three basic groups (Table 3). 


\begin{tabular}{|c|c|c|}
\hline ECOLOGICAL & SPATIAL & SOCIO-ECONOMIC \\
\hline \multicolumn{3}{|c|}{ Landfill site selection criteria } \\
\hline $1,2,3,4,6,9,10,12$, & $\begin{array}{c}5,7,11,13,14,17, \\
19,20,25,30,31\end{array}$ & $8,16,18,21,27,28,29,32$ \\
$15,22,23,24,26$ & $19,20,32$, &
\end{tabular}

Table 3. Classification of chosen criteria into basic criteria groups

The scores of each criteria obtained in the basic evaluation process would then be multiplied by weight values for criteria groups according to different scenarios (Table 3). Weight values would actually be the percentage values whose sum is $100 \%$.

Scores of each criteria from the basic evaluation process would be then multiplied by weight values for criteria groups according to different scenarios (Table 4).

Weight values would actually be the percentage values whose sum is $100 \%$.

\begin{tabular}{|c|c|c|c|c|}
\hline Basic criteria group & SC 1 & SC 2 & SC 3 & SC 4 \\
\hline EKOLOGICAL & 0.50 & 0.25 & 0.25 & 0.33 \\
\hline SPATIAL & 0.25 & 0.50 & 0.25 & 0.33 \\
\hline SOCIO-ECONOMIC & 0.25 & 0.25 & 0.50 & 0.33 \\
\hline
\end{tabular}

Table 4. Criteria weight values according to different scenarios

After multiplying the criteria values from basic evaluation by weight criteria according to different scenarios and their sum for each candidate site, the ranking of candidate sites according to different scenarios would be obtained (Table 5).

\begin{tabular}{|c|c|c|c|c|}
\hline \multirow{2}{*}{ Scenario } & SC 1 & \multicolumn{4}{|c|}{ SC 2 } & SC 3 & SC 4 \\
\cline { 2 - 5 } & \multicolumn{4}{|c|}{ Site ranks } \\
\hline \multirow{4}{*}{$\begin{array}{c}\text { Candidate } \\
\text { site }\end{array}$} & Kalenić (83.12) & $\begin{array}{c}\text { Kalenić (77.50) } \\
(63.12)\end{array}$ & Kalenić (73.32) & Kalenić (76.23) \\
\cline { 2 - 5 } & Carić (58.62) & $\begin{array}{c}\text { Bogdanović (53.25) } \\
(48.87)\end{array}$ & $\begin{array}{c}\text { Bogdanovica } \\
(47.40)\end{array}$ & $\begin{array}{c}\text { Bogdanovica } \\
(50.98)\end{array}$ \\
\cline { 2 - 5 } & Carić (45.07) & Carić (50.82) \\
\hline
\end{tabular}

Table 5. Ranking of candidate sites according to different scenarios

Through multicriteria evaluation according to different scenarios, several options and different arguments for the selection of the most suitable site are made available to decision makers. Implementation of different scenarios is based of the PROMETHEE method.

In this case, it has been shown that the location Kalenic has the best values in all four scenarios, while it is evident that the remaining two locations differ depending on scenario. The location Carić is better valued for the scenario 2, while location Bogdanovica is better valued in other three scenarios. 


\subsection{Multicriteria analysis and evaluation using GIS tools}

In selecting the landfill site in the Kolubara Region for municipal solid waste management, the GIS tools have been implemented in singling out areas to be eliminated. The areas to be eliminated have been singled out based on defined exclusion criteria. Each of exclusion criteria has been presented graphically (cartographic presentation), and corresponding areas have been identified using GIS technology. Through overlapping maps of each exclusion criteria, negative areas have been singled out that should not be further analyzed in the landfill site selection process for the municipal solid waste management. Negative areas are shown in the synthesis map (Figure 2).

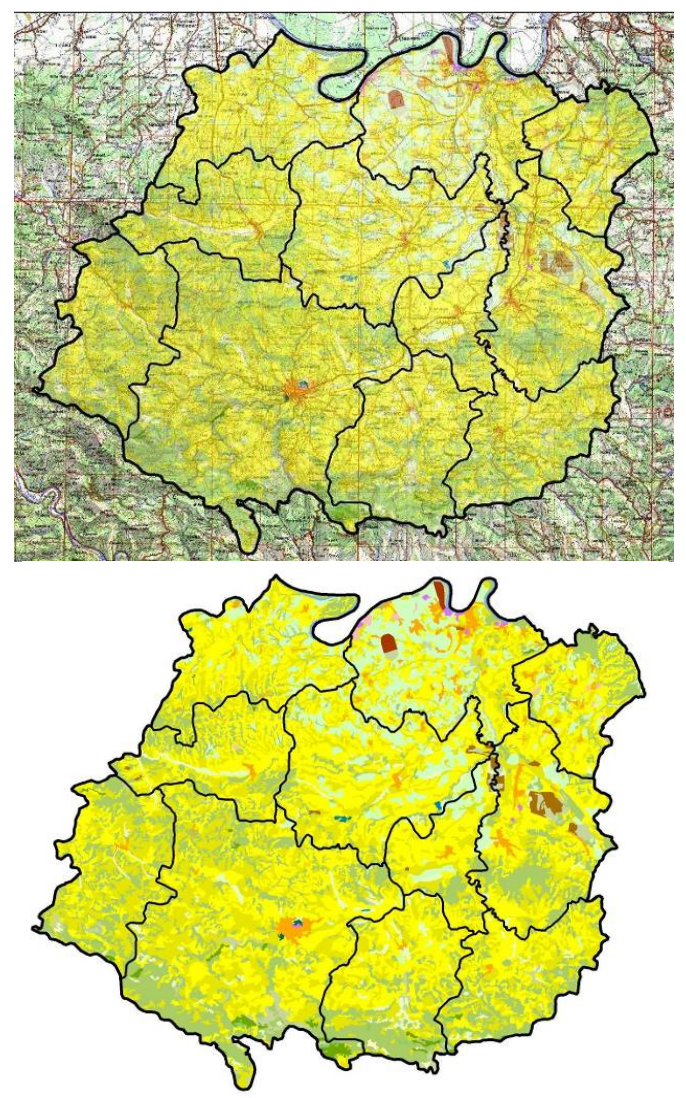

Figure 2. Analsys of land use structure based on CORINE information system [11].

Figure 2. depicts the structure of land use in Kolubara Region based on the CORINE (Coordination of Information on the Environment). The CORINE program is the European information base as support to the sustainable development policy of the European Union. The database contains data on: urban areas, crop yield, meadows, forests and natural vegetation, waters,. as well as other dynamic processes in the environment. All mentioned 
data are cartographically presented, which enables a more simple analysis of the subject area. The CORINE program was initiated in 1985. At the beginning, the program was developed and tested on 10 regions of the European Union by demonstrating the feasibility of the approach. Satellite photographs on which the CORINE database is based have been geometrically and radiometrically supplemented and with abundance of data which are in the CORINE Land Cover organized hierarchically in three levels classified in 44 classes (correspondingly presented spatial features and data). After showing positive results, in 1994 the European Environment Agency based in Copenhagen undertook the maintenance and use of the CORINE Land Cover database. Since then, the CORINE Land Cover (CLC) has been affirmed which is reflected in the fact that an increasing number of European countries are involved in the CLC project which has provided them with an opportunity to more efficiently pursue their environmental protection and sustainable development policies, as well as to carry out analyses for various needs and development strategies. Today, 64 European countries are involved in the CORINE Land Cover 2000 Project, with clearly defined and synchronized methodology for collection, processing, as well as presentation of data, in the function of the elaboration of environmental management plans [12].

In the elaboration of the "Study on the Selection of Micro-Location for the Regional Municipal Waste Landfill with Recycling Center for the Kolubara Region", the CORINE information base has not been available for Serbia, thereby for the Kolubara Region either. However, once the information on the environment from the CORINE program have become available for users in Serbia, all results from the elimination phase of landfill site selection contained in the Study have been checked and, what is even more important, confirmed. By using the CORINE program in accordance with the defined eliminating criteria for Kolubara Region, the selection of "negative" areas has been much easier and faster. The CORINE Information base to a great extent meets the needs of elimination phase in landfill site selection, thus this phase should be used as much as possible.

On the synthesis map (Figure 3), which is a final phase in the process of elimination of "negative" areas, the areas which do not satisfy basic conditions relative to the established exclusion criteria are denoted by red color. These are mainly corridors along watercourses, first category roads, distances to settlements, areas at over 300 meters above sea level, water supply sources, etc. Thus, it is the matter of exclusion criteria represented by minimum required distance of the future landfill site relative to them [13].

In the elimination phase, it is also possible to use some other criteria such as, for example, central position of a landfill relative to the Region. This means that, because of the costeffectiveness of the waste management system, i.e. transportation costs, it is necessary to position a landfill within the radius of 20 or $30 \mathrm{~km}$ relative to the central point of the Region. However, in such case, a great number of areas that merit further analysis by their characteristics can be excluded, while the problem of central positioning of a landfill can be overcome through a good organization of transfer station network in the Region. In this context, it is important to emphasize that it is not necessary to introduce a great number of exclusion criteria, but to limit the choice of exclusion criteria to the most relevant ones, as shown on the example of the Kolubara Region. 


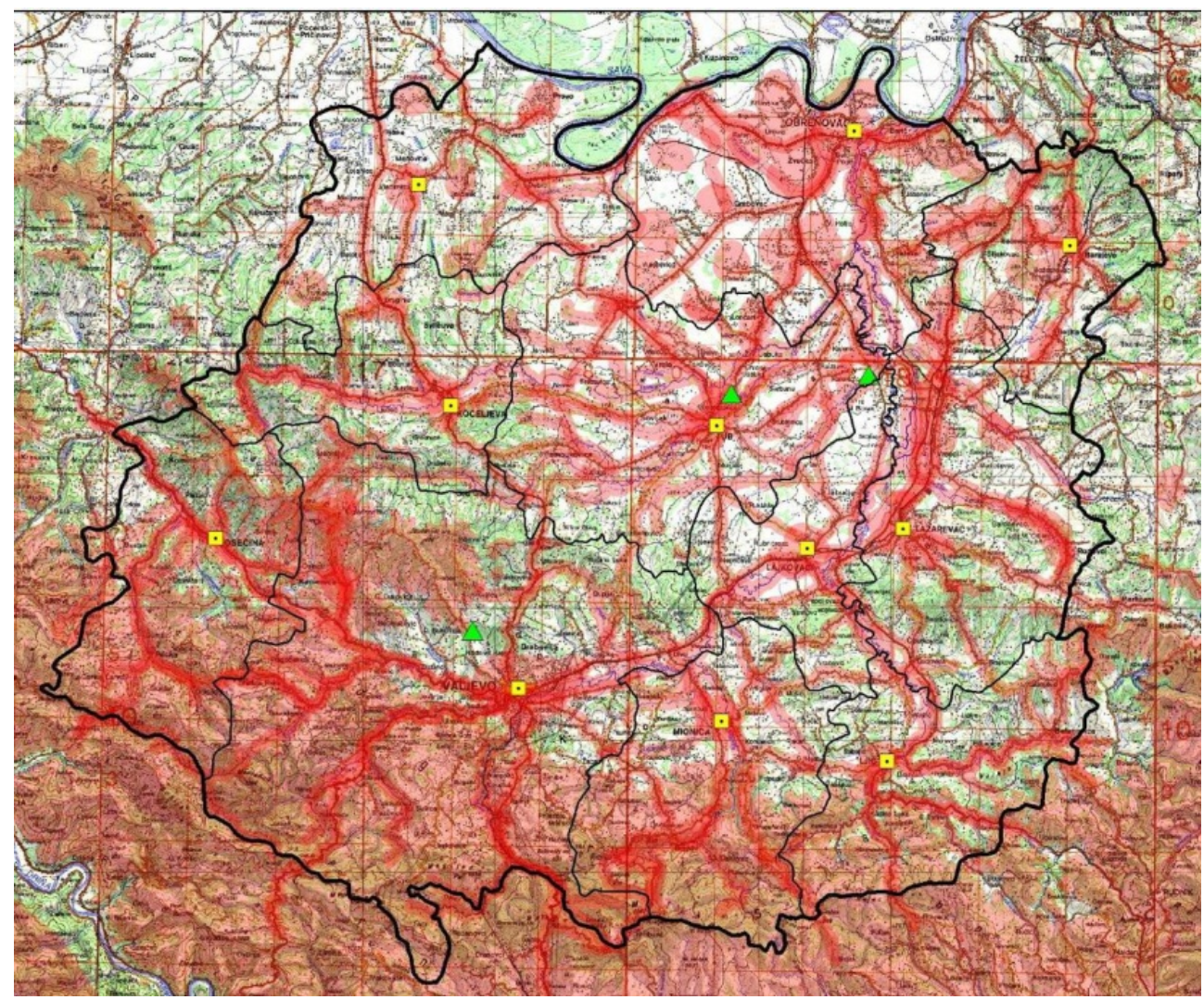

Figure 3. Suitability/elimination map

Once the consultations with relevant entities have been carried out, as well as preliminary analysis of areas that have not been eliminated in the first phase of the landfill site selection process, three sites have been singled which have been included in the process of detailed analysis and multicriteria evaluation.

The use of GIS information base in this phase of landfill site selection has considerably accelerated the process of evaluation according to 32 given criteria. Once the location Kalenić has been assessed as the most suitable one and singled out as the most acceptable one, the landfill site selection process has been completed. However, this is not where the use of GIS tools ends. Their role is also in implementation of a uniform information system for waste management which consolidates data on landfills, transfer stations, waste generation, waste flows, as well as other data important for an efficient waste management. 
In this sense, GIS tools represent an information support in the functioning of the waste management system.

\section{Conclusions}

Landfill site selection is the most sensitive task placed before the participants in the process of planning spatial organization of a waste management system, particularly in countries in which there is insufficient awareness and lack of information in the population, and, consequently, there is a resistance to plans to locate a landfill in their area, known as NIMBY (not in my backyard) syndrome. Out of these reasons, this problem is overcome through defining the elimination and basic criteria for landfill site selection based on which an multicriteria evaluation is carried out, along with mandatory inclusion of all relevant stakeholders in the process of selecting the most suitable landfill site. In the present paper, such exclusion criteria have been chosen that are appropriate to the specific space which has been the subject of our investigation, as well as according to available spatial data. In this context, the paper emphases the fact that the choice of exclusion criteria is conditioned by a specific physical properties of space. After the phase of elimination of "negative" areas, a multicriteria analysis of sites that have been nominated based on a set of basic criteria has been carried out. Altogether 32 criteria have been defined that are based on efficient functioning of a landfill, as well as on efficient environmental protection at specific landfill site and its surroundings. A multicriteria evaluation model has been offered and value scale for evaluation of each criteria defined. The multicriteria evaluation model has been also used for different scenarios. In this context, basic criteria for landfill site selection have been grouped into several basic groups, while in the evaluation process for each criteria only one of the basic groups has been evaluated. Such approach enables decision makers to choose the most suitable option and to make best decision according to their policy.

Comprehensive consideration of the problem associated with landfill site selection for physical elements of waste management system implies the use of GIS tools, thus providing a more sophisticated process of spatial analysis and searching for better options, as well as accelerating and visually enriching the process. Advantage of using GIS tools is in that it enables faster singling out and clearer presentation of suitable and unsuitable landfill sites based of previously given criteria. The paper shows the example of advantages and disadvantages, as well as possibilities of implementing GIG in regional landfill site selection for municipal solid waste management in the Kolubara Region. The GIS applications are particularly suitable for elimination phase where, based on the given exclusion criteria and spatial data, the "negative" areas within which potential landfill sites are not be searched are very quickly and easily eliminated. The entire process is presented cartographically. The possibility of implementing the CORINE Program - a uniform European information base on the environment and space usage, which is particularly suitable for elimination phase in landfill site selection as it provides abundance of geospatial data, has been highlighted. Furthermore, the possibility of efficient waste management using database in the GIS is highlighted. The system supported by such data enables quality and fast waste 
management, monitoring, waste data updating, as well as the best basis for planning waste management strategy at regional level.

\section{Author details}

Boško Josimović and Igor Marić

Institute of Architecture and Urban \& Spatial Planning of Serbia, Serbia

\section{Acknowledgement}

This work has resulted from research within the scientific project: "Sustainable spatial development of Danube area in Serbia " (TR 036036), which was financed within the program Technological development by the Ministry of Education and Science of the Republic of Rerbia from 2011 to 2014.

\section{References}

[1] Ilić M (2005) Waste Management in the Focus of Controversial Interests. In: Lechner P, editor. Waste Management. Vienna: Boku University. Pp. 95-96.

[2] Boško Josimović, Marina Ilić, Dejan Filipović (2009) Planning of Municipal Waste Management. Belgrade: Institute of Architecture and Urban \& Spatial Planning of Serbia. 157 p.

[3] Waste Management Strategy of the Republic of Serbia 2010-2019.

[4] Boško Josimović (2003) Implementation of Environmental Management System in spatial planning - master's thesis. Belgrade: Faculty of Geography. 146 p.

[5] UK Department for the Environment (1995) Landfill Design, Construction and Operation Practice.

[6] Josimović B, Marić I, Manić B (2011) Methodological approach to the determination of landfill location for municipal solid waste - Case study: Regional landfill in Kolubara region. Architecture and Urbanism. 32: 55-64.

[7] Catalano A, Zhang M, Rice J (2006) The Use of GIS to Manage, Analyze, and Visualize Data Collected During an Investigation of a Proposed Landfill. Available: http://gis.esri.com/library/userconf/proc98/.

[8] Margeta J, Prskalo G (2007) Sanitary Landfill Site Selection, Građevinar. 58. No. 12.

[9] Higgs G (2006) Integrating multi-criteria techniques with geographical information systems in waste facility location to enhance public participation. Waste Management \& Research: pp 105-117.

[10] Brans J.P, Vincke Ph (1985) Preference Ranking Organisation Method for Enrichment Evaluations - The Promitee Method for Multiple Criteria Decision Making. Management Science. 31: 647-656.

[11] Josimović B, Crnčević T (2010) Implementation of Strategic Environmental Assessment in Serbia with special reference to the Regional Plan of Waste Management. In: Santosh Kumar Sarkar, editor. Environmental Management. Rijeka: SCIYO. pp. 95-113. 
[12] CORINE Land Cover 2000, http://terrestrial.eionet.europa.eu/CLC2000.

[13] Josimović B, Krunić N (2008) Implementation of GIS in the selection of locations for regional landfill in the Kolubara Region. SPATIUM. 17: 72-77. 